\title{
The Communicative Grammar Phenomenon as the Reflection of the Anthropocentric Worldview of the Contemporary Humanitarian Discourse
} \author{
Julia V.Kapralova*1, Liliya R. Akhmerova ${ }^{2}$, Sun Miao ${ }^{3}$ \\ ${ }^{1,2}$ Kazan Federal University, Institute of Philology and Intercultural Communication, ${ }^{3}$ China University of \\ Petroleum (Hua Dong) \\ Email: ${ }^{* 1}$ afina.pallada@mail.ru, ${ }^{2}$ lavolkins15@mail.ru
}

Received: 21st October 2017 Accepted: 16th November 2017, Published: 31st December 2017

\begin{abstract}
The article highlights the actual theoretical and methodological issues of communicative grammar from the point of view of the "new" communicative trend in teaching Russian as a foreign language considering the anthropocentric worldview of the contemporary humanitarian discourse. The relevance of the stated problem is caused by the absence in the modern methodological and anthropological "picture of the world" of clear criteria for description for the separation of the "traditional" and "non-traditional" approach to communicative grammar. The authors raise the question of the continuity of methodological traditions, tracing the development of the communicative approach, revealing its theoretical prerequisites and "involvement" in the modern anthropological paradigm of humanitarian discourse. Relative-comparative methods, the use of discourse analysis techniques allowed the authors of the article to approach the anthropocentric (cultural) understanding of the reasons for shifting the interests of grammarians from the device of the language system (traditional grammar) to its functioning ("non-traditional grammar" or grammar of the "speaker"). Despite the significant differences between the three main "nontraditional" approaches (functional-communicative grammar, the theory of functional grammar and the applied theory of functional-communicative syntax), their basis is the orientation toward text and immersion in the discursive space of the language being studied. The main result of this research is the understanding of the phenomenal essence of communicative grammar as a linguistic and cultural fact, and the practical way out is the use of the methodological principles of communicative grammar as a nucleus in the modern linguodidactic model in the study of the Russian language as a foreign language.
\end{abstract}

Keywords: Functional-Communicative Grammar, Theory of Functional Grammar, FunctionalCommunicative Syntax, Anthropocentric Language Paradigm, Humanitarian Discursive Space, Method of Teaching, Russian as a Foreign Language.

\section{Introduction}

The phenomenality of grammar as a phenomenon consists in the multidimensionality of contact points with the anthropological picture of the world. A talking, thinking, feeling person is the main character in the world and in the language. His comprehension of the world, his attitude to other people and the phenomena of the world are expressed in the language and speech media he chooses. At the end of the 20th century, the idea of the anthropocentric orientation of linguistics is universally accepted. There is an identification of the speaker's thought organization and the process of optimal information transfer at the level of modern humanitarian discourse. The accumulated knowledge, materials, experiments, methods, means and techniques should be rethought at a certain point, expanding the usual boundaries of common understanding of the grammar essence. A criterion for the necessity of this process and a unifying beginning is the figure of a person, speaking person.

\section{Materials and Methods}

This original research was carried out on the basis of synthesis and analysis of the accumulated traditional and new "non-traditional" knowledge and materials in the scientific and research humanitarian space about the communicative grammar of the Russian language. The diachronic, comparative-historical and comparativecomparative methods combined with the elements of discourse analysis enabled us to identify the anthropocentric (culturological) reasons for shifting the interests of grammarians from the linguistic system (traditional grammar) to its functioning ("non-traditional grammar" or grammar of the "speaker").

\section{Results}

A paradigm of the modern educational process undergone, on the one hand, some changes in comparison with the pedagogical principles of the XX century, on the other hand, it retained the methodical continuity, a "basis property" of the postulates of the basic approaches and techniques. Thus, at the end of the 20th century, the traditional approach based on a descriptive formal grammar was replaced by new principles of teaching and 
explanation in the practice of teaching the Russian language as a foreign language (hereinafter RFL); they came back to the directions that were called the "communicative grammar", "functional-communicative grammar" and "functional grammar" in the scientific discourse. However, should we talk about the emergence of a "different" - "unconventional» - grammar, opposed to "traditional" one? The variety of the names of "new" grammar is also alarming -functional, communicative, functional and communicative. Is their semantic content identical?

At the first glance, formality, communication and functionality (in the light of the main -communicative language function) cannot be recognized as characteristic features of grammar itself, so the question of contrasting formal and semantic grammars may seem meaningless. On the other hand, if we prefer not to the grammatical language structure, but to the science of it, this opposition acquires a different meaning in the light of the concept of two-sided nature of linguistic sign (form and content) and the existence of two possible approaches to the analysis of linguistic facts -onomasiological and semasiological.

If we refer to the "New Dictionary of Methodological Terms and Concepts" [1, p. 50-51], the following methodically significant varieties are indicated in the article "Grammar": pedagogical (or traditional, practical), communicative (active or productive), functional, passive (or receptive).

Pedagogical (or practical) grammar is aimed at teaching a foreign language, it is "a reduction of the grammatical material of the language studied in accordance with the aims of learning" [1, p. 51]. In fact this is a simplified formal grammar that also contains information on both cognitive activities of a person, contextual use of grammatical forms, as well as linguistic picture of the world of the language studied.

Communicative (active, productive) grammar means "a language description that reveals the rules for functioning of the language units in speech, depending on the statement content" [1, p. 98]. In practice, such grammar sections may include "Expression of spatial relations", "Expression of temporary relations", etc. The thought movement is carried out in the direction from the content to the form (onomasiological approach) here. That is why this grammar is active: it is aimed at studying the functioning of grammatical constructions in speech (unlike traditional practical grammar, which represents the approach "from the form to the content" and thus represents the semasiological aspect of the study; it is passive (receptive) grammar). Information about the functional grammar is located in the specified dictionary in a separate dictionary entry, which is significant in itself. The term "functional grammar" is not synonymous with the term "communicative grammar", although they are united by many things: both varieties are active productive grammars with an onomasiological approach to the language facts.

Thus, one can speak of a clear contrast between two directions in teaching grammar, depending on the orientation to the onomasiological or semasiological approach, to productive or receptive types of speech activity in the modern methods of teaching a foreign language. The obvious shift in the interests of grammarians to the "active" pole is a natural phenomenon. Thus, in the well-known work "Grammar as a Science about Human"G.A. Zolotova outlined the main drawback of traditional descriptive grammar and an important requirement of modern scientific approaches to grammar -to "humanize" the grammar, to return the speaker to it [2, p. 107-113].

According to T.M. Chirko and T.M. Lomova, today the effectiveness of teaching a foreign language is assessed "in terms of the formation of students' productive skills and abilities, as well as from the point of view of the adequacy of language tools they use to the purposes and conditions of communication" [3, p. 51-55]. So there is gradually a logical modification of the idea of grammar as an object of teaching the RFL -this is a kind of "reduced" version of formal descriptive grammar, which becomes a speech grammar. "Functional grammar has grown on the basis of a traditional one; it is the same grammar, but it is being updated, not frozen, but being in the development, dynamics, not closed to dissent, but open to new observations and arguments" [4, p. 72]. The idea is also confirmed by the position of A.V. Bondarko, who has believed that "the system-structural and functional directions form a unity, but it is far from equilibrium and the uniform distribution of its components" in the linguistic theory [5, p. 5].

It is also customary to distinguish three areas of functional and grammatical research in the modern Russian philology: 1) functional-communicative grammar (FCG), based on the concept of G. A. Zolotova; 2) the theory of functional grammar (TFG), developed by a group of scientists under the guidance of corresponding member of the RAS A. V. Bondarko; 3) applied theory of functional-communicative syntax (FCC) by M. V. Vsevolodova.

1) Functional-communicative grammar connects the system concept of grammar and text analysis: significant units of language are analyzed in connection with the communicative activity of the speaker, the main object of study is the text and its grammatical models [4, p. 72].

2) The theory of functional grammar is represented by the works of scientists of the St. Petersburg school of functional grammar that have seen the value of grammatical analysis in studying the content of 
categories studied and in such a correlation of this content with the form of linguistic expression that seeks to reveal the effect of the form on the representation of actualized semantics. The TFG creates a classification, system-descriptive model of categorical grammar that the Russian grammar system describes in a series of grammars of other languages, referring to the comparison aspects, unlike the FCG, which refers to the text of one language and analyzes the speaker as the creator of this text.

Both TFG and FCG, in contrast to the "traditional" grammar, are focused on the study of how the grammar functions, and not how it is arranged. "Functioning of the units of the language structure (grammatical forms of the word, syntactic constructions and "construction lexemes") is implemented in interaction with elements of the intralinguistic and extralinguistic environment. Inclusion of this interaction in the field of research and description expands it, but it does not contradict the existing understanding of the essence of grammar, since the categorical basis of linguistic structure remains the focus of attention" [5, p. 7]. Thus, the analysis of any grammatical phenomenon presupposes a two-unit view of the student: from language position and from speech position.

3) Functional-communicative syntax (FCC) combines the tasks of teaching the RFL (functional-communicative approach) and the science of Russian language (formaldescriptive and semantic approaches), describing linguistic methods of Russian speech generation. The task of such an approach to teaching language is formulated by M. V. Vsevolodova as forming the "linguistic thinking", teaching "the language understanding as a communicative system that will enable it to be seen from the "inside" and present the possibility of other meaning configurations, other means of expression and mechanisms that operate these means in other languages" [6, p. 4]. The main objects of FCC description are: content plan (semantic speech space lexical, grammatical and lexical-grammatical semes and their value systems, which form functional-semantic categories and functional-semantic fields); expression plan (formal language units -syntaxum and utterance and objects of study - word combination and text); language mechanisms that ensure the emergence and functioning of speech constructions. The FCC concept declares the organizing role of syntax, so the central unit of study and learning is a sentence (statement) for the concept supporters, where a discourse is declared the only functioning field.

Thus, it is obvious that three directions presented demonstrate a view on grammar as an instrument of communication, the attribute of the speaking person, subordinate to the pragmatist of the speaker and semantic predetermination of the communication situation.

The beginning of active development of the theory of communicative grammar as a linguistic method coincides with the humanities science transition to the anthropocentric "platform". Communicative grammar as a new direction began to actively declare itself in the second half of the XX century (the works of G. A. Zolotova, O. A. Krylov, A.V. Bondarko, N. K. Onipenko), based on the following concepts, whose anthropocentric nature was obvious:

1) The concepts of linguistic pragmatics (attention is transferred to the speech-producing person, who is included in the "sign - sign user" relationship. This concept goes back to the works of Oxford philosophers B. Russell, J.Austin, H. Grice, J.Serl);

2) research of the structural literary studies that use grammatical categories and concepts in order to interpret the artistic text (R. O. Yakobson, I. Mukarzhovsky, Ts. Todorov);

3) The understanding of artistic text in narratology, within which a content plan and an expression plan of the text are singled out (the works of N. A. Kozhevnikova, V. Schmidt);

4) culturological phenomena of the art semiotics (Yu. M. Lotman, B.A. Uspensky);

5) Theoretical units of interpretational semantics (E. V. Paducheva).

In the domestic science the basis of the communicative grammar of the Russian language was laid by G. A. Zolotova, opposing the basic methods of "traditional" descriptive grammar to the "non-traditional" grammar (explanatory or communicative) and referring to the phenomenon of triune essence of a language unit (meaning, form and function) as the basis of the speech grammar. The modern methodology of teaching the RFL presupposes the obligatory inclusion of grammatical aspect in the speech and discourse [7, 8, 9, 10], the formation of communicative and sociolinguistic competence of students in grammar classes [11, 12].

\section{Summary}

So, in the framework of communicative grammar, the grammatical structure of a specific language is considered in accordance with the spirit of the anthropocentrism ideas as a tool for communication and thinking, of cognition of the surrounding reality, receives the status of a mentally conditioned category.

The modern methods of teaching the RFL borrowed from communicative grammar not only the basic approach to language, but the individual principles of working with modeling the units of discursive practice of the speaking person as well. The speech grammar is based on the achievements of the traditional formal-descriptive grammar (language grammar), although it is opposed to 
it in many respects. The learning goal is immersion in the discursive language space and its development through the syntactic models (from word-combinations to text). Mastering grammar is considered as a necessary condition for immersion in the space of another's language and acquaintance with the basic features of the language picture of the world of the foreign language speakers.

\section{Acknowledgement}

The research is performed according to the Russian Government Program of Competitive Growth of Kazan Federal University.

\section{References}

[1] Azimov E. G., ShchukinA.N. A New Dictionary of Methodical Terms and Concepts (Theory and Practice of Teaching Languages). - M.: Publishing House "IKAR", 2009. - $448 \mathrm{p}$.

[2] Zolotova G. A. Grammar as a Science about Human // Russian Language in the Scientific Coverage. - 2001. No. 1. - P. 107-113.

[3] ChirkoT.M., LomovaT.M. Active Grammar: to the Content Concept // Bulletin of the VSU.Series: Linguistics and Intercultural Communication. - 2002. No. 1. - P. 51-55.

[4] Zolotova G. A. On the Possibilities of Functional Language Study // Russian Language in the Scientific Coverage. - 2002. - No. 1 (3). - P. 65-74.

[5] BondarkoA.V. Theory of Functional Grammar: Introduction. Aspectuality. Temporal Localization. Taxis. - L.: Nauka, 1987. - 348 p.

[6] Vsevolodova M. V. Theory of FunctionalCommunicative Syntax. Fragment of the Applied (Pedagogical) Language Model. Textbook. - Moscow: MSU, 2000. - 501 p.

[7] UkhanovaT.V.,Kosova V.A. Russian adjectives with confixes from an anthropocentric viewpoint // Journal of Language and Literature. - 2016. - Vol. 7. No. 2. -Pp. 328-331.

[8] StarostinaO.V., GaliulinaI.R., BastrikovA.V. Synonymy of endings: frequency and rarely used forms (from experience of teaching Russian as a foreign language) // Journal of Language and Literature. - 2016.Vol. 7. No. 3. - Pp. 248-252.

[9] VarlamovaM.Yu., BochinaT.G., MiftakhovaA.N. Interactivity in teaching a foreign language // Journal of Language and Literature. - 2016. - Vol. 7. No. 3. - Pp. 190-194.

[10] Erofeeva I.V.The Methodology of Teaching Russian as A Foreign Language to Slavonic Speaking Students // Procedia Social and Behavioral Sciences(2015). Volume 186, 13 May 2015. - Pp. 1095-1100.

[11] GaliulinaI.R., YapparovaV.N., StarostinaO.V.
Foreign student's social competence formation on Russian speech listening lessons (by the example of regional studies texts) // Modern Journal of Language Teaching Methods. - Special issue, - December, 2016. Pp. 37-42.

[12] SadykovaI.A., GilazetdinovaG.H., YapparovaV.N. Speech is Silver but Silence is Gold (Once Again to the Issue of What Russian Silence Means). - The Social Sciences, 2015. - Volume: 10, Issue: 7. - Pp. 19351939. 